\title{
Controllable Generation of a Submillimeter Single Bubble in Molten Metal Using a Low-Pressure Macrosized Cavity
}

\author{
ALEXANDER KONOVALENKO, PER SKÖLD, PAVEL KUDINOV, \\ SEVOSTIAN BECHTA, and DMITRY GRISHCHENKO
}

\begin{abstract}
We develop a method for generation of a single gas bubble in a pool of molten metal. The method can be useful for applications and research studies where a controllable generation of a single submillimeter bubble in opaque hot liquid is required. The method resolves difficulties with bubble detachment from the orifice, wettability issues, capillary channel and orifice surfaces degradation due to contact with corrosive hot liquid, etc. The macrosized, 5- to $50-\mathrm{mm}^{3}$ cavity is drilled in the solid part of the pool. Flushing the cavity with gas, vacuuming it to low pressure, as well as sealing and consequent remelting cause cavity implosion due to a few orders in magnitude pressure difference between the cavity and the molten pool. We experimentally demonstrate a controllable production of single bubbles ranging from a few milliliters down to submillimeter size. The uncertainties in size and bubble release timing are estimated and compared with experimental observations for bubbles ranging within 0.16 to $4 \mathrm{~mm}$ in equivalent-volume sphere diameter. Our results are obtained in heavy liquid metals such as Wood's and Lead-Bismuth eutectics at $353 \mathrm{~K}$ to $423 \mathrm{~K}\left(80{ }^{\circ} \mathrm{C}\right.$ to $\left.150{ }^{\circ} \mathrm{C}\right)$.
\end{abstract}

DOI: $10.1007 / \mathrm{s} 11663-017-0914-\mathrm{z}$

(C) The Author(s) 2017. This article is published with open access at Springerlink.com

\section{INTRODUCTION}

GAS bubbles injected into a liquid are used in a variety of industrial applications and experimental research such as metallurgy, chemistry, food science, biology, and of course, the physics of the multiphase flows. Regardless of the purpose for bubble injection, the typical tasks are to determine or control an amount of gas, number, and size of bubbles being injected into the liquid phase. These tasks are usually accomplished by employing application-specific methods of bubble generation, detection, and characterization. In the case when fluid is a nontransparent and chemically aggressive (e.g., corrosive liquids at high temperature), the practical implementation can be a complex task requiring costly solutions. The optimal choice of the gas injection method, allowing predefined generation of the gas amount with acceptable accuracy, may significantly simplify system design and lower the cost of a facility.

Available in literature, experimental approaches, where millimeter or submillimeter gas bubble injection into a liquid is realized, can be divided into two categories: (1) techniques allowing mass production of the bubbles and (2) those where a single bubble can be produced. There are many methods where generated

ALEXANDER KONOVALENKO, PER SKÖLD, PAVEL KUDINOV, SEVOSTIAN BECHTA, and DMITRY GRISHCHENKO are with the Nuclear Power Safety Division, Royal Institute of Technology (KTH), Albanova, 10691 Stockholm, Sweden. Contact email: kono@kth.se

Manuscript submitted June 9, 2016.

Article published online January 31, 2017. bubbles have broad size distribution and a few where size is accurately controlled.

As an example of a bubble mass production technique, Fujikawa et al. proposed a micro-air-bubble generation device based on a rotating porous plate. ${ }^{[1]}$ The method allows generation of 10 to $30 \mu \mathrm{m}$ in size air bubbles dispersed in water. The authors validated the predicted mean bubble radius against experimental observations. In another experimental study, a conventional gas injection into liquid through the orifice was analyzed for the effect of different geometries of the orifice. ${ }^{[2]}$ Importantly, these studies demonstrated that a slit-like shape is an energetically efficient orifice geometry for submillimeter bubble generation where slit length does not affect the resulting bubble size. The microfluidic flow-focusing devices became of interest to researchers in many studies because of advances and availability of nanofabrication technologies. The micrometer in size channels for the gas and fluid phases can be easily fabricated. With a good reproducibility, the formation and pinch-off the bubbles below $50 \mu \mathrm{m}$ can be studied. ${ }^{[3]}$ The effect of flow-focusing geometry of the device has been studied in Reference 4. An overview of the recent advances in development of the energy efficient fluidic oscillators can be found in Reference 5 .

The variety of single-bubble generation techniques is limited in comparison with the multiple bubble production, in particular, for the case when size and detachment time of submillimeter bubble are desired to be well controlled. This is because of the technical challenges in accurate control of capillary forces at microscopic scale. In References 6 through 8, a method based on acoustical excitations or pressure waves propagating through the 
gas channel up to the nozzle submerged into pool of liquid was successfully applied to generate submillimeter single bubbles.

The detection and characterization of the injected bubble is often required, e.g., for tracking of the bubble motion and calibration of the bubble injection system.

During the past few decades, there have been achievements in development of bubble measurement techniques based on various principles, physical effects, and properties of the gas and liquid phases. A selection of intrusive and nonintrusive bubble measurement techniques with relevant references are summarized in Table I. The bubble traveling in liquid can be detected by simple optical observations, optical ${ }^{[9]}$ and electrical $^{[10-12]}$ probe measurements, advanced ultrasound Doppler velocimetry (UDV) ${ }^{[14-16]}$ X-ray imaging ${ }^{[17]}$ neutron radiography, ${ }^{[26]}$ and sophisticated resonant spectroscopy ${ }^{[21-25]}$ allowing measurements of the bubble size distribution in the pool.

Both intrusive and nonintrusive bubble detection methods can be divided into three groups where the following types of sensors are used: electromagnetic, acoustic, and optical (including X-ray and neutron imaging). The nonintrusive methods of bubble measurements are preferable in most of the applications. Nevertheless, the choice of the technique generally depends on the required measurement accuracy in particular applications, rising bubble size, and properties of the liquid and experimental conditions (such as liquid temperature, its chemistry, tank dimensions, relative velocity of the gas to liquid phases, etc). In addition, the instrumentation cost is often a significant factor.

Few bubble generation techniques and bubble detection methods have been applied in heavy liquid metals (HLMs). The Lead-Bismuth eutectics (LBE) is a typical example of HLM having high corrosivity. The main factors challenging the implementation of existing bubble detection techniques and limiting the selection of materials that can be used as probes for such liquids are as follows:

- Nontransparency of HLM

- High temperature of the molten mixture

- Corrosivity

- Low electrical impedance (limiting usage of electromagnetic sensing)
Significant differences in properties of HLM and nonmetallic liquids as well as operating conditions, e.g.:

- Surface tension, viscosity, density

- Wettability of the apparatus surfaces

- Operating pressure and temperature

imply that either bubble generation or measurement technique developed and validated in non-HLM liquid may give unsatisfying results if applied to HLM. For example, the surface wettability of instrumentation is difficult to control and keep constant under the extreme experimental conditions and fluid properties such as temperature and corrosivity. Therefore, conventional bubble injection with capillary channel, syringe, or any other method involving outlet orifice in the design can be potentially problematic for reliable detachment of a single bubble. Therefore, we postulated the following requirements to the design of bubble generation device (BGD):

- Absence of gas channels or orifice surfaces in contact with molten HLM to avoid problems due to channel plugging by impurities or impurities effects on surface wettability and bubble detachment

- Simple and inexpensive bubble size measuring instrumentation preferably based on the measurement of the amount of gas injected

- Acceptable rate of the gas bubble generation

In this article, we report a newly developed method of bubble generation in HLM that satisfies requirements and provides reproducible generation of the bubbles ranging within 0.16 to $4 \mathrm{~mm}$ in diameter. The coverage of the wide range of more than an order of magnitude is required in studies of the bubble drag coefficient, which is crucial for safety analysis and design of the fourth generation of nuclear power plants. One safety issue for compact pool type designs of lead and lead-bismuth cooled fast reactors is steam generator tube rupture or leakage. ${ }^{[33]}$ If steam bubbles leaking from a steam generator tube into the heavy liquid metal HLM coolant can reach the reactor core, they can cause an increase of reactivity or cause damage to the reactor fuel due to local dryout effect. ${ }^{[33]}$ The steam bubbles transport in the primary system of an HLM cooled reactor, and the possibility that bubbles can reach the core is highly sensitive to the terminal rise velocity for submillimeter bubbles. ${ }^{[34]}$ Unfortunately, there are no data available

Table I. Main Types of Bubble Detection and Characterization Techniques

\begin{tabular}{|c|c|}
\hline Nonintrusive Methods & Intrusive Methods \\
\hline $\begin{array}{l}\text { Electromagnetic sensing } \\
\text { Capacitive or inductive measurements } \\
\text { Conductivity of the liquid channel } \\
\text { Acoustical methods: } \\
\text { Ultrasound techniques (UDV, etc. })^{[14-16]} \\
\text { Bubble noise detection }{ }^{[17-20]} \\
\text { Resonant acoustics (spectroscopy, excitation, etc. })^{[21-25]} \\
\text { X-ray imaging } \\
\text { Neutron radiography } \\
\text { Optical measurements (LDV, photo, video, etc. })^{[2,6,8,27-32]}\end{array}$ & $\begin{array}{l}\text { Optical probe }{ }^{[9]} \\
\text { Conductivity probes }{ }^{[10-12]} \\
\text { Hot wire anemometer }\end{array}$ \\
\hline
\end{tabular}


on the terminal velocity for small bubbles in HLM. This work provides a description of the experimental installation for generation of small bubbles in HLM as a first step toward development of experimental setup for measurements of the terminal bubble rise velocity. The goal is to achieve (1) good reproducibility in terms of bubble size from a few millimeters down to submillimeter scale in equivalent diameter and (2) acceptable timing between consequent bubble injections. Experimental results and uncertainty as well as advantages and disadvantages of the method are discussed in detail.

\section{EXPERIMENTAL APPROACH AND PRINCIPLES OF OPERATION}

The experimental facility consists of two main parts: the tank filled with molten HLM and BGD installed at its bottom as schematically shown in Figure 1(a). On top of the molten metal surface, a $10-\mathrm{mm}$ layer of glycerol is used to capture generated gas bubbles at the interface of the two fluids. The video recording of the interface is performed using a Canon 60D camera at $50 \mathrm{fps}$ and $1920 \times 1080$ resolution fitted with macro lens model Sigma $150 \mathrm{~mm}$ 1:2.8 APO MACRO DG HSM (not shown). The video recording allows bubble monitoring and characterization. The main tank is a stainless steel cylindrical vessel with an internal diameter of $54 \mathrm{~mm}$ and a height of $51 \mathrm{~mm}$. It is heated using resistive wire wound on the outer lateral surface. The bottom of the tank is a 9-mm-thick stainless steel plate with an imbedded cylindrical heater (bottom heaters as shown in the figure) installed in the proximity to the threaded opening where the neck of BGD is mounted.

The bubble generation device mounted under the main tank consists of the bottom neck with its heater, the needle valve, and two additional Swagelok valves connecting the BGD to the inert gas and vacuum pump as illustrated in Figure 1(a). The fore-line vacuum pump (not shown) allows quick vacuumization of the system down to $50 \mathrm{~Pa}(0.5 \mathrm{mBar})$. The pressure in the system is measured with an analog pressure gauge (Figure 1(b)) allowing measurements down to $1 \mathrm{kPa}(10 \mathrm{mBar})$. The bottom neck is a stainless steel cylinder with internal dimensions of $15 \mathrm{~mm}$ high and $13 \mathrm{~mm}$ in diameter. The $\varnothing 3-\mathrm{mm}$ hole at the bottom of the neck can be closed by the needle valve. The neck has a separately controlled resistive heater allowing for quick melting of the HLM. For Wood's metal and LBE, the few hundred Watts of resistive heating power is sufficient for melting and heating of about $110 \mathrm{~mL}$ of material up to $473 \mathrm{~K}$ $\left(200{ }^{\circ} \mathrm{C}\right)$. For the temperature monitoring, three thermocouples are installed in the main tank close to the main tank bottom (TC1), inside the bottom plate (TC2), and near the $3-\mathrm{mm}$ hole separating the needle valve from the neck compartment (TC3).

The principle of operation and all phases of the experimental procedure of bubble generation and injection into molten HLM pool are illustrated in Figures 2(a) through (f). At first, the HLM is melted in the main tank while the bottom part of the pool (neck) is kept cold, as illustrated in Figure 1(a). The macrosized

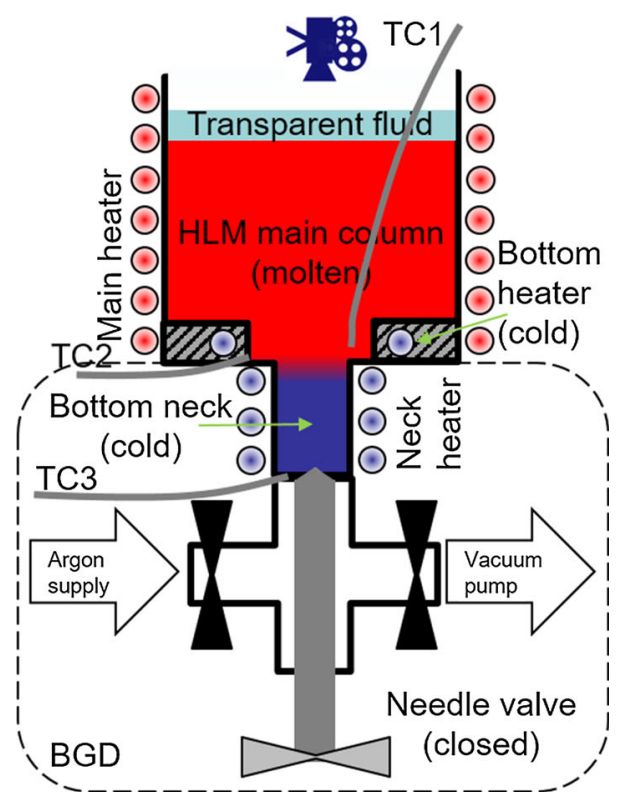

(a)

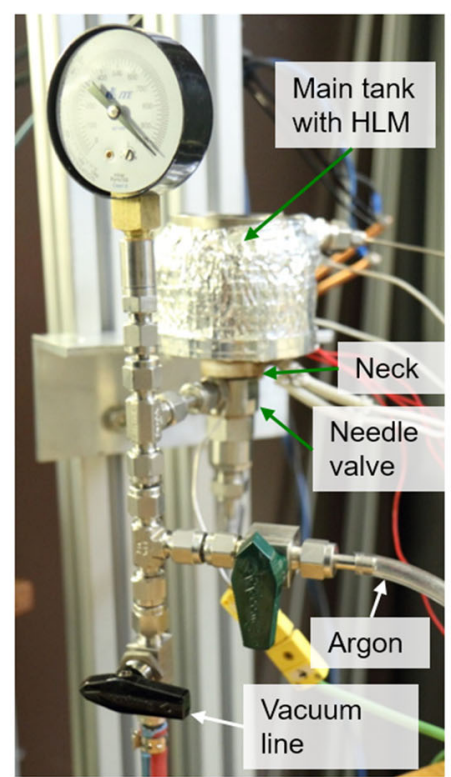

(b)

Fig. 1-Schematic (a) and photographic (b) images of the single bubble-generating device (BGD) (Color figure online).

5- to $50-\mathrm{mm}^{3}$ cavity (two diameters and heights were used: $\varnothing 1.5 \times 3.3 \mathrm{~mm}$ and $\varnothing 2.5 \times 4.3 \mathrm{~mm}$ ) is created in the neck with solidified metal (Figure 2(a)). The air trapped in the cavity is flushed away by alternating the vacuum pumping and Ar gas refilling, while the needle valve is kept opened (Figure 2(b)). Then the Ar supply valve is closed and vacuuming is performed until the desired low pressure (Figure 2(c)) is achieved. At the same time, the neck and bottom tank heaters are turned on. At about $10 \mathrm{~K}$ to $15 \mathrm{~K}\left(-263{ }^{\circ} \mathrm{C}\right.$ to $\left.-258{ }^{\circ} \mathrm{C}\right)$ below the HLM melting point, the needle valve is closed to minimize the effect of the thermal gas expansion in the cavity (Figure 2(d)). The melting of the heavy metal in the neck eventually occurs. Due to a few orders of 
magnitude pressure difference between the low pressure gas in the cavity and HLM in the pool, the cavity collapses into a small bubble (Figure 2(e)). From visual observations and temperature measurements in the neck, we have estimated that the bubble rise to the HLM surface covered with glycerin is delayed by about 10 to 40 seconds. This delay can be explained by the fact that cavity implosion occurs earlier than melting of the metal in the neck is complete. Additional time is necessary for melting of solid metal above the bubble (shown schematically in Figure 2(e) as blue region). It is interesting to note that a systematic offset of about 5 to $7 \mathrm{~mm}$ was observed between the tank center and final location of the bubble at the HLM surface. There is a possible phenomenon that the rise of the bubble can begin together when surrounded not completely by molten LBE shell. Due to the high thermal conductivity of the LBE and its high density, such a solidified shell will not rise far from the cavity original position and will eventually melt.

Our experimental observations suggest that single bubble generation occurs when the ratio of the initial cavity length to its diameter is about 3 to 1 . For the larger ratios, multiple bubble generation may occur. We found that the diameter of the bottom neck should be several times larger than the maximal cavity diameter; otherwise, there is a risk that the bubble can stick on the wall with rough or nonwettable HLM surface. As can appear from Figures 2(e) and (f), it is possible that during the cavity implosion, the resulting bubble may attach and fasten to the bottom of the neck or tip of the needle valve. Therefore, metal heating should be provided such that melting starts near the side wall and at the bottom of the neck. Then, the molten HLM is relocating downward filling the bottom of the cavity and neck-needle valve entrance prior to the implosion. The previously mentioned design features are the main advantages of the proposed bubble generation technique: where the contact of the gas bubble to solid surfaces is avoided.

Currently, the minimum period of bubble injection into HLM is about 12 to 15 minutes with all operations performed manually. Automatization of the valves and drilling and optimization of the timing for heating and cooling of the neck would be required to speed up the experimental procedure.

The prediction of the resulting bubble volume $V_{\mathrm{b}}$ and size, or equivalent volume sphere diameter $D_{\mathrm{b}}$, can be obtained from the equation of state of the ideal gas:

$$
\begin{gathered}
V_{\mathrm{b}}=\frac{\pi d_{\mathrm{cav}}^{2} h_{\mathrm{cav}}}{4} \times \frac{\rho_{\mathrm{vac}}}{\rho_{\mathrm{b}}}=\frac{\pi d_{\mathrm{cav}}^{2} h_{\mathrm{cav}}}{4} \times \frac{P_{\mathrm{vac}}}{P_{\mathrm{b}}} \times \frac{T_{\mathrm{b}}}{T_{\mathrm{vac}}} \\
D_{\mathrm{b}}=2\left(\frac{3}{4 \pi} V_{\mathrm{b}}\right)^{1 / 3}=\left(\frac{3}{2} d_{\mathrm{cav}}^{2} h_{\mathrm{cav}} \times \frac{P_{\mathrm{vac}}}{P_{\mathrm{b}}} \times \frac{T_{\mathrm{b}}}{T_{\mathrm{vac}}}\right)^{1 / 3}
\end{gathered}
$$

where $\rho_{\text {vac }}, P_{\text {vac }}$, and $T_{\text {vac }}$ are density, pressure, and temperature of the gas when the vacuumed cavity is sealed, whereas, $\rho_{\mathrm{b}}, P_{\mathrm{b}}$, and $T_{\mathrm{b}}$ are corresponding gas properties when the bubble is formed in HLM. $h_{\text {cav }}$ and $d_{\text {cav }}$ are initial height and diameter of the cavity, respectively.

In Figure 3(a), the estimated bubble size is plotted as a function of the ratio of the pressure in the vacuumed cavity $P_{\text {vac }}$ and system pressure $P_{\text {sys }}=P_{\text {atm }}+P_{\mathrm{HLM}} \cong$ $P_{\mathrm{b}}$. The hydraulic head pressure $P_{\mathrm{HLM}}$ of about $5.1 \mathrm{kPa}$ (51 mBar) is taken into account for LBE fluid. The plots are provided for two cavity dimensions (diameter and effective height: $\varnothing 1.5 \times 3.3 \mathrm{~mm}$ and $\varnothing 2.5 \times 4.3 \mathrm{~mm}$ ). A small conical volume at the top of the cavity produced by the drilling tip is taken into account as an effective cavity height $h_{\text {cav }}$. The typical gas thermal expansion [ 13 pet for temperature changes from $373 \mathrm{~K}$ to $423 \mathrm{~K}$ $\left(100{ }^{\circ} \mathrm{C}\right.$ to $\left.150{ }^{\circ} \mathrm{C}\right)$ ] is also taken into account. As seen from the plots, the submillimeter size of the bubble can be achieved already for 10 pct of the atmospheric pressure.

It is important to estimate the uncertainty in bubble size. The relative error in bubble equivalent diameter $\delta D_{\mathrm{b}} / D_{\mathrm{b}}$ can be calculated as a function of uncertain $\delta x$ parameters involved in Eq. [2]:

$$
\begin{aligned}
& \pm \frac{\delta D_{\mathrm{b}}}{D_{\mathrm{b}}}=\left[\frac{V_{\mathrm{b}}+\delta V_{\mathrm{b}}}{V_{\mathrm{b}}}\right]^{1 / 3}-1 \\
& \quad=\left[\left(1 \pm \frac{\delta d_{\mathrm{cav}}}{d_{\text {cav }}}\right)^{2}\left(1 \pm \frac{\delta h_{\mathrm{cav}}}{h_{\mathrm{cav}}}\right) \times \frac{\left(1 \pm \frac{\delta P_{\text {vac }}}{P_{\text {vac }}}\right)}{\left(1 \mp \frac{\delta P_{\mathrm{b}}}{P_{\mathrm{b}}}\right)} \times \frac{\left(1 \pm \frac{\delta T_{\mathrm{b}}}{T_{\mathrm{b}}}\right)}{\left(1 \mp \frac{\delta T_{\mathrm{vac}}}{T_{\text {vac }}}\right)}\right]^{1 / 3}-1
\end{aligned}
$$

The relative error $\delta D_{\mathrm{b}} / D_{\mathrm{b}}$ in Eq. [3] is estimated as positive and as negative, and the corresponding minimum and maximum boundaries are calculated by using the appropriate sign for each input uncertain parameter $\delta x / x$. In Figure 3(b), the error in equivalent volume spherical bubble diameter as a function of $h_{\text {cav }}$ is shown for cavities having 1.5 and $2.5 \mathrm{~mm}$ diameter. As seen from both curves the estimated uncertainty is below 10 pct for $h_{\text {cav }}>4 \mathrm{~mm}$. In our experiments, the major uncertainty contributors are errors in pressure measurements $\left(\delta P_{\text {vac }}=100 \mathrm{~Pa}(1 \mathrm{mBar})\right.$ and $\delta P_{\mathrm{b}}=10 \mathrm{kPa}(100$ $\mathrm{mBar})$ ) and cavity dimensions $\left(\delta d_{\mathrm{cav}} \approx 0.1 \mathrm{~mm}\right.$ due to wobbling of the drilling bit despite usage of a special center-aligning adapter and $\delta h_{\text {cav }} \sim 0.25 \mathrm{~mm}$ ). The conservative $\delta T_{\text {gas, HLM }}=10 \mathrm{~K}$ uncertainty in temperature causes minor influence for a typical $T_{\text {gas,HLM }}$ $\in(370 \mathrm{~K} ; 470 \mathrm{~K})$ working range. Naturally, the volumetrically larger cavities will collapse into bubbles having smaller uncertainties in its size. Thus, for accurate bubble generation, it is advised to use larger cavities and a smaller $P_{\mathrm{vac}} / P_{\text {sys }}$ ratio. For the applications where high vacuum is not available or not accurately controlled, an increase in overhead pressure $P_{\mathrm{b}}$ in the HLM tank is another alternative to reach a low $P_{\mathrm{vac}} / P_{\mathrm{b}}$ ratio. The uncertainty curves in Figure $3(\mathrm{~b})$ are rough theoretical estimates. The experimentally measured bubbles and relevant measurement errors are discussed in the next section. 


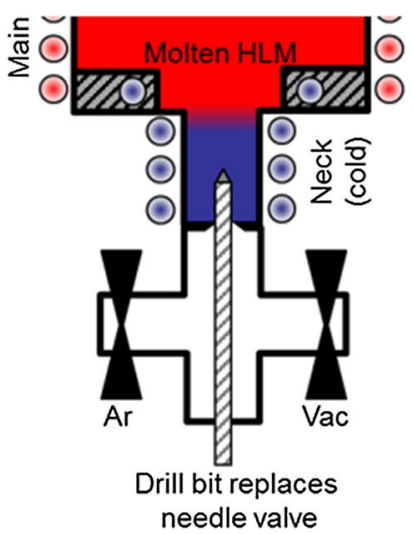

(a)

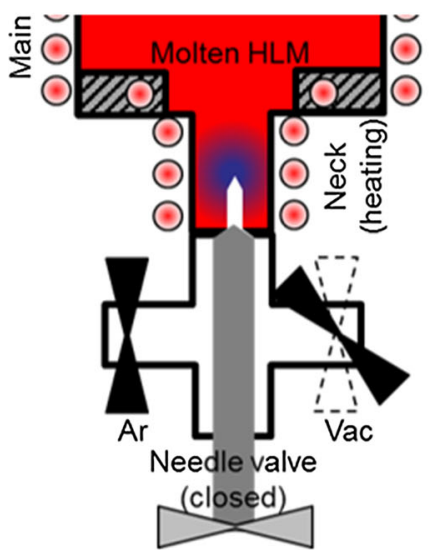

(d)

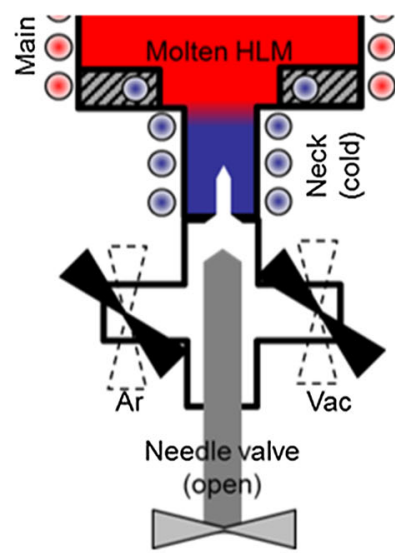

(b)

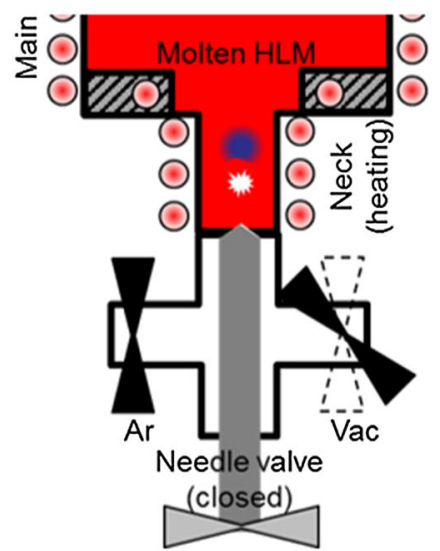

(e)

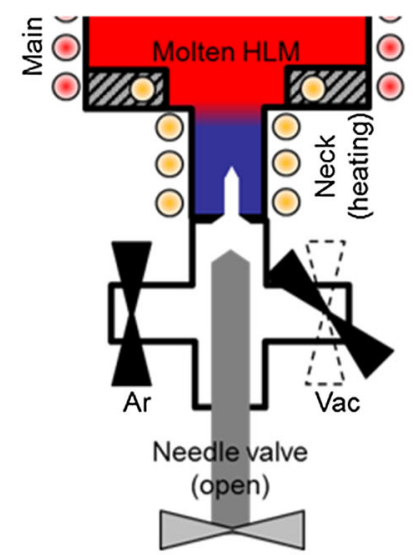

(c)

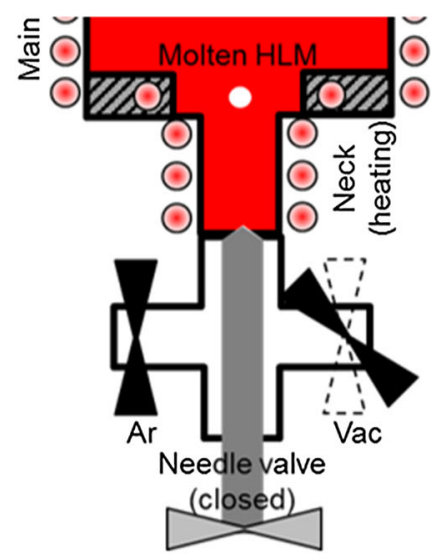

(f)

Fig. 2-Experimental procedure on single bubble generation in molten HLM: cavity creation by drilling (a), flushing air from cavity $(b)$, vacuuming and neck preheating $(c)$, neck melting $(d)$, cavity implosion $(e)$, and bubble rise $(f)$ (Color figure online).

\section{RESULTS AND ANALYSIS}

The proposed single-bubble generation technique has been tested in a few exploratory tests with Wood's metal (observed melting temperature in the tests $\left.t_{\mathrm{m}} \in[343 \mathrm{~K} ; 349 \mathrm{~K}]\left(\left[70^{\circ} \mathrm{C} ; 76^{\circ} \mathrm{C}\right]\right)\right)$ and $\mathrm{LBE} \quad\left(t_{\mathrm{m}} \in\right.$ $\left.[397 \mathrm{~K} ; 399 \mathrm{~K}]\left(\left[124^{\circ} \mathrm{C} ; 126^{\circ} \mathrm{C}\right]\right)\right)$. A layer of glycerol was provided on top of the metal layer to capture the bubble. Initially we believed that it would be easier to work with Wood's metal rather than with LBE due to differences in melting temperatures. In practice, however, we observed fast chemical degradation of the glycerol if residing on top of the liquid Wood's. Another issue was that rising bubbles systematically stuck below the glycerol/Wood's interface. To avoid evaporation of the glycerol obstructing visualization, the silicon oil is recommended to use for future tests.

The tests conditions, main results, and measurements accuracy are given in Table II. The snapshots obtained in video monitoring of the generated 1.57-, 0.55-, and $0.16-\mathrm{mm}$ bubbles are demonstrated in Figures 4 through 6 for corresponding tests E4, E5, and E8. In all figures, three stages of experiment are shown: prior, during, and after the bubble passage through the HLM-glycerol interface. In addition, a zoomed-in image of the bubble is shown in the insert or in a separate subfigure. The length scale is provided (see also the 1.5-mm-thick thermocouple TC1 visible in some figures).

In general, the dynamics of the bubble passing through the liquid-liquid interface is a complex phenomenon (e.g., see References 35 and 36). The rising bubble can cross the horizontal liquid-liquid interface in different regimes. Depending on bubble size, its rise velocity, and the physical properties of the lower and upper fluids, the bubble can pass through the interface, delay its passage, or stick at the interface. Detailed study of such phenomena are out of scope of this work. Nevertheless, the case of a permanently or temporarily trapped (floating) bubble at the interface is of particular interest in our studies. In this case, video recordings from the top can be used to estimate the bubble diameter. In all tests with LBE, the bubble is slowly floating above the interface exposing its surface in upper liquid (glycerol) and being partly immersed in the molten metal for some time. In contrast, in some tests with Wood's metal, the generated bubbles tend to be trapped under the interface making estimations of the size more difficult. In both cases, the stuck bubble can be detached from the interface after some time or by applying an external disturbance.

Upon the HLM-Glycerol interface penetration by the bubble, both the bubble and the interface are subject to 
substantial deformations due to interfacial, elastic, and viscous forces. ${ }^{[35]}$ This deformation is observed in our tests, as clearly seen in the second subfigures of Figures 4 through 6 . Shortly after the bubble appearance, the interface deformation quickly diminishes and contours of the bubble can be well resolved, as seen in

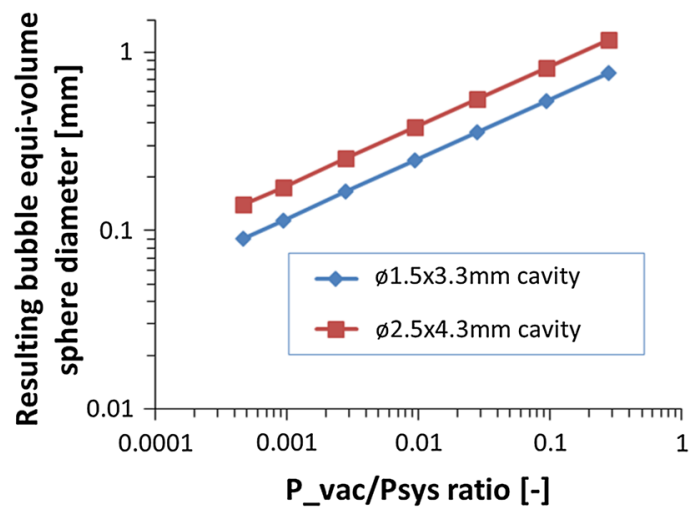

(a)

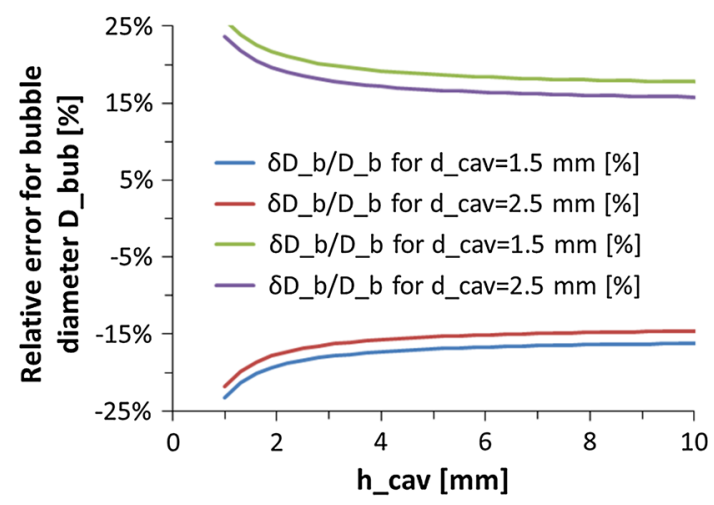

(b)

Fig. 3-Predicted bubble diameter $D_{\mathrm{b}}$ as a function of pressure ratio (a) and uncertainty estimate $\frac{\delta D_{\mathrm{b}}}{D_{\mathrm{b}}}(b)$. the third subfigures and insets in Figures 4 and 5, as well as in the right image in Figure 6. One common feature in all our tests is the appearance of an irregularly shaped diffuse reflection spot surrounding the bubble. It resides at the interface and remains there even after bubble pinch-off from the interface. The spot is clearly visible in the bottom images in Figures 4 through 6 . We believe that this is a thin layer of impurities such as oxides originating from the initial cavity surface. Formation of the oxidic layer can take place during cavity drilling, which is performed in air. Upon cavity implosion at a low temperature below $423 \mathrm{~K}\left(150^{\circ} \mathrm{C}\right)$, the oxide is neither dissolved nor melted. The color and optical reflectivity of the bubble-following spot is, in fact, very similar to oxidic film floating at the HLM surface as seen in Figures 4 and 5 (first snapshots).

In some tests, we observed very small satellite bubbles (e.g., depicted by the white circle in the third subfigure in Figure 6). The origin of such small bubbles is not clear. It might be that cavity collapse might sometimes lead to formation of multiple bubbles instead of a single one. These small bubbles are arriving at the interface later than the bubble itself.

Another phenomenon that was sometimes observed in close investigation of the video recording was a breakup of the main bubble at impact at the glycerol-HLM interface. At the time of the impact, the bubble is squeezed between the liquids by the inertia forces into a thin layer of gas. Before it recovers to a spheroidal shape, it can break, leaving a few small satellite bubbles. For instance, two satellite bubbles can be seen in the bottom image in Figure 6 (inside the dashed white rectangle, near the main bubble). The smallest bubble of about $0.16 \mathrm{~mm}$ in diameter has been obtained by cavity evacuation to the lowest pressure of about $50 \mathrm{~Pa}$ (0.5 mBar) achieved with a used vacuum pump.

The predicted bubble diameter is compared with an experimentally measured one. As seen in Table II and Figure 7, the relative difference is below 20 pct. Statistically, our measurements overestimate the bubble

Table II. Experimental Test Conditions and Main Results

\begin{tabular}{|c|c|c|c|c|c|c|c|c|}
\hline \multirow{2}{*}{$\frac{\text { Used HLM/Transparent Fluids }}{\text { Test number }}$} & \multicolumn{4}{|c|}{ Wood's/Glycerol } & \multicolumn{4}{|c|}{ LBE/Glycerol } \\
\hline & E1 & $\mathrm{E} 2$ & E3 & E4 & E5 & E6 & E7 & E8 \\
\hline $\begin{array}{l}\text { Initial cavity diameter (mm) } \\
\text { and height (mm) }\end{array}$ & $\varnothing 2.5 \times 9$ & $\varnothing 2.5 \times 9$ & $\varnothing 2.5 \times 9$ & $\varnothing 2.5 \times 9$ & $\varnothing 1.5 \times 3$ & $\varnothing 1.5 \times 3$ & $\varnothing 1.5 \times 3$ & $\varnothing 1.5 \times 3$ \\
\hline $\begin{array}{l}\text { Initial gas temperature when } \\
\text { cavity is sealed }\end{array}$ & $\begin{array}{l}303 \mathrm{~K} \\
\left(30^{\circ} \mathrm{C}\right)\end{array}$ & $\begin{array}{l}293 \mathrm{~K} \\
\left(20^{\circ} \mathrm{C}\right)\end{array}$ & $\begin{array}{l}317 \mathrm{~K} \\
\left(44^{\circ} \mathrm{C}\right)\end{array}$ & $\begin{array}{l}353 \mathrm{~K} \\
\left(80^{\circ} \mathrm{C}\right)\end{array}$ & $\begin{array}{l}353 \mathrm{~K} \\
\left(80^{\circ} \mathrm{C}\right)\end{array}$ & $\begin{array}{l}370 \mathrm{~K} \\
\left(97^{\circ} \mathrm{C}\right)\end{array}$ & $\begin{array}{l}373 \mathrm{~K} \\
\left(100^{\circ} \mathrm{C}\right)\end{array}$ & $\begin{array}{l}373 \mathrm{~K} \\
\left(100{ }^{\circ} \mathrm{C}\right)\end{array}$ \\
\hline $\begin{array}{l}\text { Final HLM temperature upon } \\
\text { bubble release }\end{array}$ & $\begin{array}{l}373 \mathrm{~K} \\
\left(100^{\circ} \mathrm{C}\right)\end{array}$ & $\begin{array}{l}373 \mathrm{~K} \\
\left(100{ }^{\circ} \mathrm{C}\right)\end{array}$ & $\begin{array}{l}373 \mathrm{~K} \\
\left(100{ }^{\circ} \mathrm{C}\right)\end{array}$ & $\begin{array}{l}423 \mathrm{~K} \\
\left(150^{\circ} \mathrm{C}\right)\end{array}$ & $\begin{array}{l}423 \mathrm{~K} \\
\left(150^{\circ} \mathrm{C}\right)\end{array}$ & $\begin{array}{l}423 \mathrm{~K} \\
\left(150^{\circ} \mathrm{C}\right)\end{array}$ & $\begin{array}{l}423 \mathrm{~K} \\
\left(150^{\circ} \mathrm{C}\right)\end{array}$ & $\begin{array}{l}423 \mathrm{~K} \\
\left(150{ }^{\circ} \mathrm{C}\right)\end{array}$ \\
\hline Vacuum pressure $(\mathrm{Pa})$ & 50 & 1 & 1 & 3 & 1 & 1 & 1 & $\mathrm{n} / \mathrm{a}(*)$ \\
\hline Expected bubble diameter (mm) & 3.77 & 1.04 & 1.01 & 1.46 & 0.51 & 0.50 & 0.50 & - \\
\hline Measured bubble diameter (mm) & 4.30 & 0.98 & 1.10 & 1.57 & 0.55 & 0.59 & 0.45 & 0.16 \\
\hline $\begin{array}{l}\text { Relative bubble size difference } \\
\text { (measured } v s \text { expected) (pct) }\end{array}$ & 14.0 & -5.3 & 9.1 & 7.3 & 7.6 & 17.3 & -10.3 & - \\
\hline Image resolution $(\mathrm{px} / \mathrm{mm})$ & 8.1 & 8.1 & 8.1 & 12.6 & 29.9 & 30.1 & 32.3 & 28.9 \\
\hline Single pixel size (mm) & 0.123 & 0.123 & 0.124 & 0.080 & 0.033 & 0.033 & 0.031 & 0.035 \\
\hline $\begin{array}{l}\text { Bubble diameter measurement } \\
\text { accuracy down to single pixel (pct) }\end{array}$ & \pm 2.9 & \pm 12.6 & \pm 11.2 & \pm 5.1 & \pm 6.1 & \pm 5.6 & \pm 6.9 & \pm 21.6 \\
\hline
\end{tabular}

(*) Minimal pressure achievable by the pump is about $50 \mathrm{~Pa}$, which is below the analog gauge accuracy. 


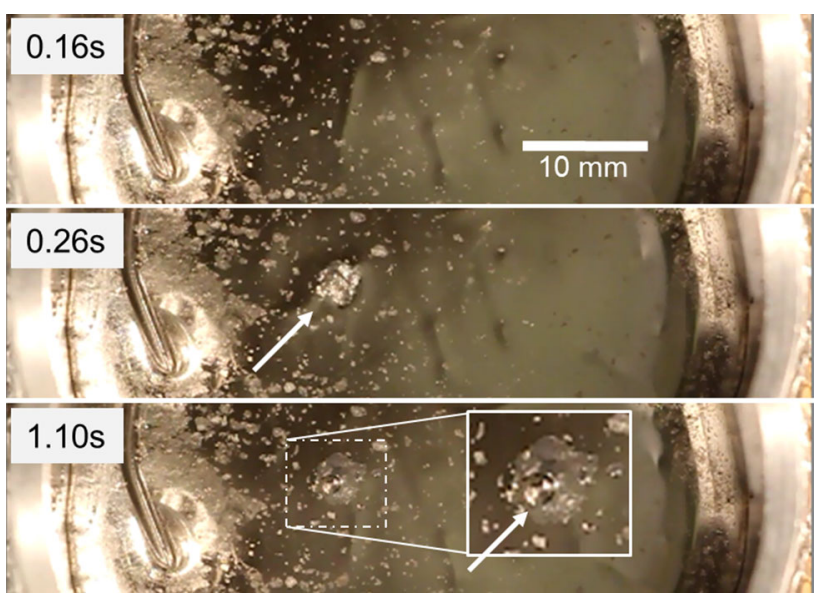

Fig. 4 -Snapshots of the $1.57-\mathrm{mm}$ bubble raised to the LBE-Glycerol interface in test E4: prior bubble breakthrough (top), deformation of the interface and emerged bubble indicated by arrow (middle and bottom), and settlement of the bubble (bottom). The relative timestamp is shown in the top-left corner, while the magnified bubble image is in the inset of the last (bottom) snapshot.

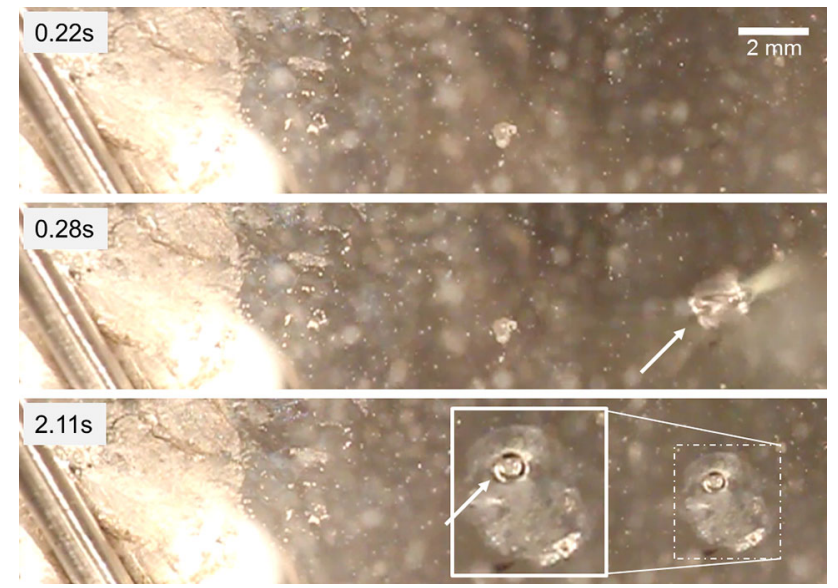

Fig. 5- Snapshots of the $0.55-\mathrm{mm}$ bubble raised to the LBE-Glycerol interface in test E5: prior bubble breakthrough (top), deformation of the interface and emerged bubble indicated by arrow (middle and bottom), and settlement of the bubble (bottom). The relative timestamp is shown in the top-left corner, while the magnified bubble image is in the inset of the last (bottom) snapshot.
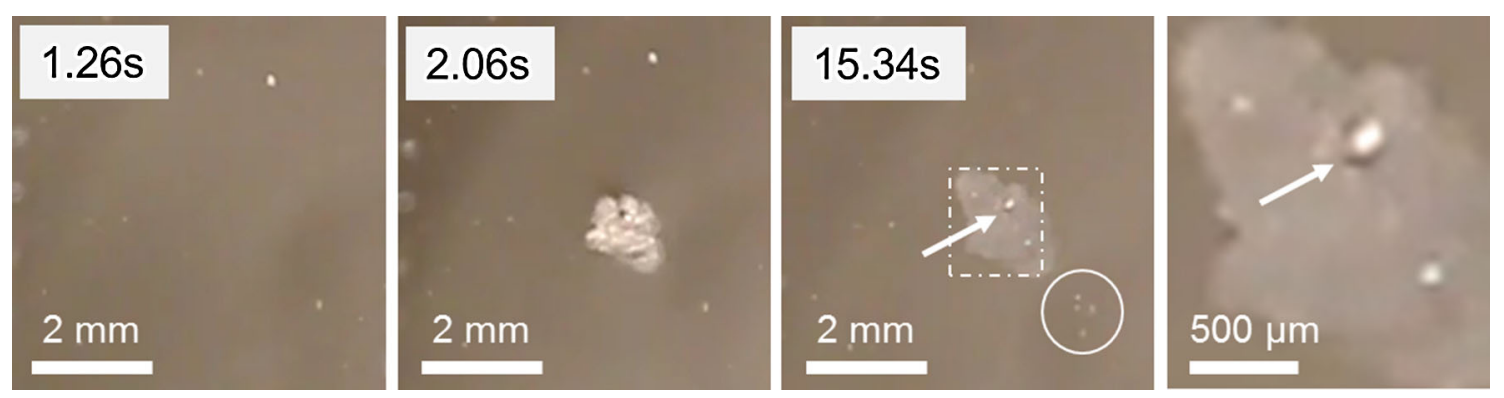

Fig. 6- Snapshots of the 0.16-mm bubble raised to the LBE-Glycerol interface in test E8: prior bubble breakthrough (left), deformation of the interface and emerged bubble (second from left), and settlement of the bubble indicated by arrow (third and fourth from left). The circle (third from left image) indicates the late arrival of oxidic particles. The relative timestamp is shown in the top-left corner, while the magnified bubble image is in the right subfigure.

diameter because the optical axis of the camera is aligned normal to the fluid-fluid interface and we measure bubble size in the lateral plane. The bubble may not be exactly spherical due to the effect of interfacial forces that may cause lens-like deformation of the bubble. In other words, the gas bubble stretches along the interface plane and seems to be larger than its equivalent volume diameter predicted by the gas cavity dimensions and initial conditions (pressure and temperature).

The bubble diameter is measured with accuracy provided in the last row of Table II. Depending on optical zoom and distance from the camera to the HLM surface, the image resolution is varying from 8 to 32 pixels per millimeter. The overall measurement error is comparable or even below relative difference between measured and expected bubble diameter.

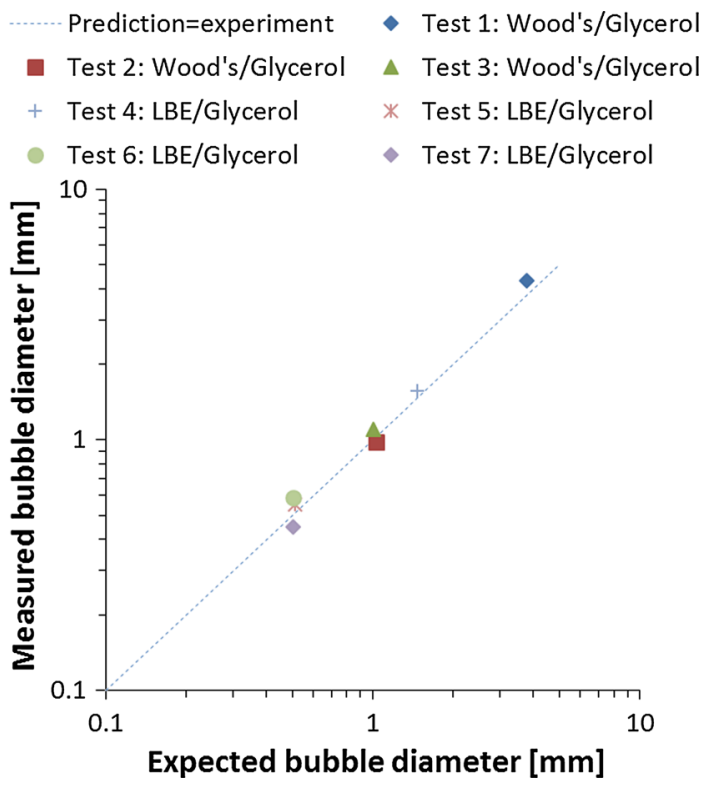

Fig. 7-Experimentally measured bubble size against predicted values for selected tests in molten Wood's metal and LBE. 


\section{CONCLUSION}

A concept of the method for generation of a single gas bubble in a pool of molten metal using low-pressure solid cavities is demonstrated in this work. The submillimeter-size single bubbles can be created from macrosize cavities. The advantages of this methods are low cost, reusable components, no capillary channel, and orifice-bubble interactions that can lead to bubble sticking to solid surfaces and good accuracy in the estimation of the bubble size. The main current difficulty with the method is detection of the time of the bubble departure. The method has been successfully validated in a set of exploratory tests with Wood's metal, LBE, and Argon bubbles.

At present, the uncertainty of the method is estimated $\sim 3$ to 20 pct in resulting bubble diameter (mainly due to the visualization technique used in this work). An improvement in visualization such as additional highspeed monitoring of the bubble from a side view can help to reduce the uncertainties. According to our theoretical estimations, the accuracy better than $15 \mathrm{pct}$ can be achieved for 0.1- to 1-mm size bubbles if a digital pressure gauge is used and the cavity length is controlled with uncertainty less than $0.25 \mathrm{~mm}$. The time between consecutive bubbles injections can be decreased by introducing automation of the experimental procedure, e.g., computer-controlled temperature (melt freezing, and re-melting) combined with automated drilling. Moreover, fabrication of the cavity in an inert or vacuum environment may prevent formation of an oxidic layer at the cavity surfaces. It is believed that thin film following the rising bubble up to the HLM surface are the fragments of that oxidic layer. The origin of small satellite bubbles, which were sometimes observed in the tests, has to be clarified in future work.

\section{ACKNOWLEDGMENTS}

This work is supported by the MAXSIMA (Methodology, Analysis and eXperiments for the "Safety In MYRRHA Assessment") project funded by the European Commission under Grant 323312. The authors are grateful to Ph.D. student Marti Jeltsov and Dr. Walter Villanueva for their valuable comments that improved the quality of this work.

\section{OPEN ACCESS}

This article is distributed under the terms of the Creative Commons Attribution 4.0 International License (http://creativecommons.org/licenses/by/4.0/), which permits unrestricted use, distribution, and reproduction in any medium, provided you give appropriate credit to the original author(s) and the source, provide a link to the Creative Commons license, and indicate if changes were made.

\section{REFERENCES}

1. S. Fujikawa, R. Zhang, S. Hayama, and G. Peng: Int. J. Multiphase Flow, 2003, vol. 29, pp. 1221-36.

2. K. Terasaka, Y. Sasada, D. Kobayashi, and S. Fujioka: J. Chem. Eng. Jpn., 2011, vol. 44 (3), pp. 140-45.

3. W. Hoeve, B. Dollet, M. Versluis, and D. Lohse: Phys. Fluids, 2011, vol. 23, p. 092001.

4. A. Salari, M. Azad, F. Shalchi, M. Shafii, and A. Hooshmand: World Academy Sci. Eng. Tech., 2012, vol. 69, pp. 276-77.

5. V. Tesar: Chem. Eng. Res. Des., 2014, vol. 92 (9), pp. 1603-15.

6. T. Sanada, M. Watanabe, T. Fukano, and A. Kariyasaki: Chem. Eng. Sci., 2005, vol. 60, pp. 4886-900.

7. A. Najafi, Z. Xu, and J. Masliyah: Chem. Eng. Sci., 2008, vol. 63, pp. 1779-87.

8. M. Shirota, T. Sanada, A. Sato, and M. Watanabe: Phys. Fluids, 2008, vol. 20, p. 043301.

9. A. Cartellier and E. Barrau: Int. J. Multiphase Flow, 1998, vol. 24, pp. $1265-94$.

10. Y. Mori, K. Hijikata, and I. Kuriyama: Trans. ASME, 1977, vol. 99 , p. 404.

11. N. Iguchi, T. Nakatani, and H. Kawabata: Metall. Mater. Trans. $B, 1997$, vol. 28B, pp. 409-16.

12. A. Castillejos and J. Brimacombe: Metall. Trans. B, 1989, vol. $20 \mathrm{~B}$, p. 595.

13. H. Toral: J. Phys. E: Sci. Instrum., 1981, vol. 14, p. 822.

14. D. Censor, V. Newhouse, T. Vontz, and H. Ortega: IEEE Trans. Biomed. Eng., 1988, vol. 35 (9), p. 740.

15. C. Zhang, S. Eckert, and G. Gerbeth: Int. J. Multiphase Flow, 2005, vol. 31, pp. 824-42.

16. A. Andruszkiewicz, K. Eckert, S. Eckert, and S. Odenbach: Eur. Phys. J. Spec. Top., 2013, vol. 220, pp. 53-62.

17. Online document: M. Wendel, A. Ibrahim, D. Felde and B. Riemer, Gas Bubble Formation in Stagnant and Flowing Mercury. ASME Digital collection, ASME/JSME 2007 5th Joint Fluid. Eng. Conf., Paper No. FEDSM2007-37435, pp. 409-14, San Diego, CA, 2007, $\mathrm{http}$ //proceedings.asmedigitalcollection.asme.org/proceeding.aspx? articleID $=1597923$. Accessed 22 December 2016 .

18. R. Andreini, J. Foster, and R. Callen: Metall. Trans. B, 1977, vol. 8 B, p. 625.

19. M. Schneider and J. Evans: Metall. Mater. Trans. B, 2006, vol. 37B, p. 333.

20. P. Marcolongo, J. Evans, and D. Steingart: Metall. Mater. Trans. $B$, 2007, vol. 38B, p. 389.

21. N. Sinha: Philos. Mag., 2003, vol. 83 (24), pp. 2815-27.

22. Online document: M. Cavaro, C. Payan, S. Mensah, J. Moysan, and J.-P. Jeannot: Linear and nonlinear resonant acoustic spectroscopy of micro bubble clouds. Acoust. Soc. Am., vol. 16, paper 045003, Proc. 17th Int. Conf. Nonlin. Elast. in Mat., Cefalu, Sicily, Italy, 2012. Doi: 10.1121/1.4748260. Accessed 22 December 2016.

23. Online document: M. Cavaro: Apport de l'acoustique non linéaire à la caractérisation de l'engazement du sodium liquide. de l'Université de la Méditerranée, $\mathrm{PhD}$ thesis, Aix-Marseille II, 2010. http://www.theses.fr/2010AIX22106.pdf. Accessed 22 December 2016.

24. M. Cavaro and C. Payan: Microbubble histogram reconstruction by nonlinear frequency mixing. Acoust. Soc. Am., vol. 19, paper 030111, Proc. Meet. Acoust, Montreal, Canada, 2013. doi: 10.1121/ 1.4799048. Accessed 22 December 2016.

25. W. Zhang, S. Spencer, and P. Coghill: Miner. Eng., 2012, vols. 36-8, pp. $45-52$.

26. K. Mishima and T. Hibiki: Nucl. Eng. Des., 1998, vol. 184, pp. 183-201.

27. L. Parkinson, R. Sedev, D. Fornasiero, and J. Ralston: J. Colloid Interface Sci., 2008, vol. 322, pp. 168-72.

28. T. Argo and P. Wilson: J. Acoust. Soc. Am., 2008, vol. 123, no. 6, pp EL121-5.

29. P. Marco, W. Grassi, and G. Memoli: Int. J. Therm. Sci., 2003, vol. 42, pp. 435- 46 .

30. P.M.I. Dias: Ph.D. Dissertation, von Karman Institute-ULB, Brussels, Belgium, 1999.

31. N. Hassan, M. Khan, and M. Rasul: WSEAS Trans. Fluid Mech., 2008, vol. 3 (3), p. 261. 
32. G. Celata, F. D'Annibale, P. Marco, G. Memoli, and A. Tomiyama: Exp. Therm. Fluid Sci., 2007, vol. 31, pp. 609-23.

33. P. Kudinov and T.N. Dinh: ELSY Report No DEL/09/29, Evaluation approach and case set-up for simulation of consequences of the SGTR event, Royal Institute of Technology (KTH), Stockholm, Sweden, January, 2010

34. Online document: M. Jeltsov and P. Kudinov, Simulation of a Steam Bubble Transport in the Primary System of the Pool Type
Lead Cooled Fast Reactors. 14th Int. Top. Meet. Nuc. Reactor Therm. Hydraul. (NURETH-14), paper 300, Toronto, Ontario, Canada, Sep. 25-29, 2011. https://inis.iaea.org/search/search. aspx?orig_q $=$ RN:47071390. Accessed 22 December 2016.

35. N. Dietrich, S. Pncin, S. Pheulpin, and H.Z. Li: Transp. Phenom., 2008, vol. 54 (3), p. 594.

36. R. Bonhomme, J. Magnaudet, F. Duval, and B. Piar: J. Fluid Mech., 2012, vol. 707, pp. 405-43. 